\title{
An investigation into reading strategies used by Vietnamese non-English major students at Kien Giang University
}

\author{
Nguyen Thi Ngoc Minh ${ }^{1 *}$, Nguyen Thuy $\mathrm{Nga}^{2}$ \\ ${ }^{1}$ Kien Giang University, Vietnam \\ ${ }^{2}$ Ho Chi Minh City Open University, Vietnam \\ *Corresponding author: ntnminh@vnkgu.edu.vn
}

\begin{abstract}
ARTICLE INFO
ABSTRACT

DOI: $10.46223 / \mathrm{HCMCOUJS.}$ soci.en.9.2.265.2019

Received: November $11^{\text {th }}, 2019$

Revised: December $9^{\text {th }}, 2019$

Accepted: December 13 $3^{\text {th }}, 2019$

Keywords:

cognitive reading strategies, metacognitive reading strategies, reading strategies, support reading strategies

This paper aimed at investigating the frequencies of reading strategies employed by Vietnamese non-English major students while taking a reading comprehension test at Kien Giang University. Data was collected through a questionnaire delivered to 117 sophomores who majored in Economics, Accounting and Construction at Kien Giang University. The results from the descriptive statistics showed that Vietnamese non-English majors were medium strategy users. Of the three types of reading strategies, cognitive strategies were the most frequently used, followed by metacognitive and support reading strategies. Out of 27 reading strategies, students reportedly used item number 14 "I read the text again for better understanding." at the highest frequency while rating item number 2 "I determined what the type of the text is." the least frequency.
\end{abstract}

\section{Introduction}

Reading is regarded as one of the most crucial skills for English learners since it is the primary means for gaining access to a wide range of information. Carrell, Devine, and Eskey (1984) do emphasize that out of the four macro skills, reading has the greatest effect on students' success, especially for ESL and EFL students. It is of great importance not only as a language skill itself but as a language input for the development of the other three skills. With better reading skills, both ESL and EFL readers are believed easier to improve in all academic areas without a native-English environment.

Reading, however, is a complex process. Even native speakers of English face difficulties and challenges when dealing with long academic texts at colleges or universities. It is, therefore, understandable that reading in a second or foreign language can place even greater demands and is even more challenging. Based on a study of 41 state educational agencies, Kindler (2002) reports that only $18.7 \%$ of ESL students meet the state standards in English reading comprehension. In spite of putting more effort into a comprehension of English text, they still struggle to comprehend what they have read. There are a variety of factors attributed to this failure in reading comprehension of ESL/EFL learners such as reading fluency, vocabulary knowledge, reading strategy or working memory (Johnston \& Kirby, 2006; 
Macaruso \& Shankweiler, 2010), and the main reason might possibly be the result of insufficient knowledge of reading strategies (Ouellettee \& Beers, 2010). Reading strategies are deliberate activities or tactics used by readers so that they are able to understand the reading texts better (Paris, Wasik, \& Turner, 1991). Appropriate application of reading strategies can assist students in dealing with complicated texts more efficiently. It is, therefore, expected that students are able to master this skill when they are often exposed to a variety of reading strategies.

\section{Literature review}

\subsection{Definition of reading strategies}

Garner (1987) defines reading strategies as conscious processes that active learners employ many times to compensate for comprehension failure. Similarly, Pani (2004) describes reading strategies as the mental activity conducted deliberately by readers to understand what they have read. Afflerbach, Pearson, and Paris (2008) provide a definition of reading strategy by explaining the difference between "reading strategies" and "reading skills" which are sometimes used interchangeably to illustrate the same process. While the former refers to actions or plans which are employed deliberately and intentionally to decode texts, understand words, and construct meaning, the latter operates automatically without the reader's conscious control. He finally asserts that reading strategies are actions or behaviors that can be consciously controlled by readers.

Although different researchers variously conceptualize reading strategies, they all agree that a deliberate application of these strategies can help enhance reading performance. In this paper, therefore, reading strategies are defined as actions or techniques consciously performed by readers to resolve problems emerging while reading and overcome their comprehension failures.

\subsection{Classification of reading strategies}

The classification used by this study is built upon Sheorey and Mokhtari's research (2001). Sheorey and Mokhtari arrange reading strategies into three broad groups: metacognitive, cognitive and support reading strategies. This categorization is developed from the theoretical framework of MARSI proposed by Mokhtari and Reichard (2000) to measure learners' strategy use while reading academic texts. More specifically, Sheorey and Mokhtari (ibid) describe metacognitive reading strategies as purposefully planned actions utilized by readers to monitor their reading. Examples of metacognitive strategies are having a purpose in mind, previewing the length and organization of the text, or predicting text meaning. Unlike metacognitive reading strategies, cognitive reading strategies seem more directly connected with a specific learning task. Cognitive reading strategies are "localized techniques" that readers often employ while working directly with the reading material (Sheorey \& Mokhtari, 2001). Using prior knowledge or rereading are typical examples of this category. Support strategies, according to Sheorey and Mokhtari (2001), refer to techniques in reading comprehension such as using dictionaries to improve reading comprehension. This category has not been stated in previous reading classifications proposed by O'Malley and Chamot (1990), Oxford (1990). However, its important role in the reading learning process cannot be underestimated. 


\subsection{Previous studies}

In a review of second language reading research, cognitive reading strategies have been of wide interest to linguistic researchers. Ozek and Civelek (2006) employed two different methods: questionnaire and Think-Aloud Protocol (TAP) to find out cognitive reading strategies generally used by the $1^{\text {st }}$ and the $4^{\text {th }}$ year students at Dicle University. The data collected from the questionnaire revealed significant differences in the use of cognitive reading strategies. The results of the TAPs analysis showed that the students used only one strategy, namely "relating the title to the text content" in the pre-reading phase. As for the while-reading phase, "using the dictionary parsimoniously" was the most effectively employed strategy. However, none of the post-reading strategies was reportedly utilized by the participants.

Nguyen and Trinh (2011) attempted to investigate which metacognitive reading strategies are being used by EFL Vietnamese learners and which problems might prevent them from using other strategies. The population was 84 students from grade 11 of a high school in a remote area of the Mekong Delta in Vietnam. Data for the study were collected through a questionnaire, reading comprehension test, and interview. The results showed that learners used global and support strategies less frequently than problem-solving ones. Besides, the interview data indicated that learners faced problems in using metacognitive strategies such as lack of knowledge of cognition, regulation of cognition, and intrinsic motivation.

The online learning environment is gradually prevailing for teachers and students nowadays. Research on online reading strategies is thus absolutely necessary. Leon and Tarrayo (2014) sought to identify strategies employed by 100 Filipino high school students when reading online materials. Data collected through the survey - Online Survey of Reading Strategies revealed that students used different strategies when they approached online reading texts. From the three categories of strategies, students reportedly employed cognitive strategies at the most, followed by metacognitive and support reading strategies.

Adapting the questionnaire from Ozek and Civelek's study (2006), Asmara (2017) carried out a study to analyze the utilization of reading strategies in reading comprehension. A self-report questionnaire was sent to 30 Senior High school students in Rancaekek, Indonesia. The outcomes of the study revealed that only four cognitive reading strategies were regularly used by more than half of the respondents with "having the picture of the events in the text in mind" as the most frequent reading strategies.

Few empirical research on reading strategies has been carried out in Vietnam. Besides, the population of these studies were mainly English major students, high school students or students from English centers. There has been little in-depth research on the use of reading strategies among non-English major students during a reading test in Vietnam and especially in Kien Giang province. This is the rationale for the current study. By investigating reading strategies used by Vietnamese non-English major students during a test at Kien Giang University, this study hopes to add further evidence on this topic.

\section{Methodology}

\subsection{Participants}

The research consisted of 120 sophomores randomly selected from three academic majors including Economics, Accounting and Construction at Kien Giang University. The rationale behind choosing these majors was that they made up a large number of students at the 
school. The ages of the sample ranged from 19 to 22 . All of the participants were native speakers of Vietnamese and reported having studied English for seven years in secondary and high schools plus at least one year in the university. At the time of this research, the participants had just finished English 3, and their English proficiency level was regarded as intermediate.

\subsection{Instruments}

Based on the objectives of the study, the students were asked to complete a questionnaire about the methods and reading strategies they often employ during reading tests at school.

The questionnaire items were mainly adapted from the Survey of Reading Strategies (SORS) in Sheorey and Mokhtari's study (2001), in which 21 out of 27 statements were extracted from SORS and the rest was from Oxford et al.' study (2001). In fact, the SORS includes 28 statements. Several of them, however, were excluded from the study because of the two following reasons. First, some statements have similar meanings such as "pay attention to reading" and "stay focus on reading". The author decided to select only the statement "stay focus on reading" to avoid making confusion for the students. Second, some others were not test-taking strategies, which cannot be applied during a test. Furthermore, items numbered 6, 13, 17, 18, 19 and 27 were added from Oxford's Reading Strategy Questionnaire (Oxford, 2004) to diversify the range of reading strategies in the questionnaire. The results of the reliability test for the questionnaire suggested that this instrument was reliable enough to measure reading strategies used by Vietnamese non-English major students with the Cronbach's alpha of .739 for metacognitive strategies, .776 for cognitive strategies, and .705 for support strategies.

In order to avoid ambiguity in meaning, the questionnaire was translated into Vietnamese. The translated version was double checked by two of author's colleagues experienced in teaching English to non-English major students to make sure that all the items were translated accurately and clearly. A 5-point Likert Scale was employed for each statement in the questionnaire. Participants were required to choose the option that best speaks for their opinions.

\section{Results}

The aim of the study was to discover the reading strategies most frequently used by Vietnamese non-English major students at Kien Giang University. In order to answer this question, mean scores were calculated.

\section{Table 1}

Students' mean scores of employing all strategies and each individual category.

\begin{tabular}{|l|c|c|c|}
\hline & M & SD & Frequency scale \\
\hline Overall reading strategies & $\mathbf{3 . 1 6}$ & $\mathbf{. 1 1}$ & Medium \\
\hline Cognitive reading strategies & 3.37 & .78 & Medium \\
\hline Metacognitive reading strategies & 3.23 & .75 & Medium \\
\hline Support reading strategies & 2.88 & .89 & Medium \\
\hline
\end{tabular}

Source: The researcher's data analysis 
According to Oxford (1990), means between 1.0 and 2.4 are viewed as low level, between 2.5 and 3.4 as medium level, and means of 3.5 or above as high level of use. It can be seen from Table 1 that the mean score for overall reading strategies was 3.16, which suggests that students' overall strategy use was at a medium level. The employment of each individual category was also rated medium. Of the three categories, cognitive reading strategies received the highest mean score of 3.37, slightly higher than the score for metacognitive reading strategies $(M=3.23)$. In contrast, support reading strategies got the lowest mean score of 2.88 .

\section{Table 2}

Most and least frequently used strategies

\begin{tabular}{|c|c|c|c|c|c|}
\hline \multicolumn{3}{|c|}{ Most frequently used strategies } & \multicolumn{3}{|c|}{ Least frequently used strategies } \\
\hline Strategies & M & SD & Strategies & M & $\mathrm{SD}$ \\
\hline $\begin{array}{l}\text { I read the text again for } \\
\text { better understanding. }\end{array}$ & 4.01 & .76 & $\begin{array}{l}\text { I determined what the } \\
\text { type of text is }\end{array}$ & 2.17 & .99 \\
\hline $\begin{array}{l}\text { I skimmed the text quickly } \\
\text { for understanding the } \\
\text { general idea of the given } \\
\text { text. }\end{array}$ & 3.95 & .86 & $\begin{array}{l}\text { I asked myself questions } \\
\text { when having a problem } \\
\text { understanding }\end{array}$ & 2.22 & .83 \\
\hline $\begin{array}{l}\text { I used prior knowledge to } \\
\text { help complete the text. }\end{array}$ & 3.91 & .78 & $\begin{array}{l}\text { I determined what to read } \\
\text { and what to ignore }\end{array}$ & 2.32 & .90 \\
\hline I skipped unknown words. & 3.88 & .73 & $\begin{array}{l}\text { I took notes while } \\
\text { reading }\end{array}$ & 2.35 & .68 \\
\hline
\end{tabular}

Source: The researcher's data analysis

As for the four most frequently used strategies, three of them fell into the cognitive category, of which "I read the text again for better understanding." was the most common strategy. The second-ranking strategy was "I skimmed the text quickly for understanding the general idea of the given text.", the only metacognitive strategy in this set of four. It was followed by the two cognitive reading strategies "I used prior knowledge to help complete the text." and "I skipped unknown words." In contrast, the least frequent reading strategies belonged to the support and metacognitive categories. Specifically, "I determined what the type of the text is." was the least used strategy. The other three reading strategies of this level were "I asked myself questions when having problem understanding", "I determined what to read and what to ignore.", and "I took notes while reading."

\section{Discussion}

The results of descriptive statistics showed that students' overall reading strategies fell into the moderate use group, which indicated that Vietnamese non-English major students at Kien Giang University occasionally employed reading strategies when doing reading comprehension tests. Although English is not their major, all participants reported having studied the subject at least 7 years before entering university. They therefore more or less have 
background knowledge of English. Additionally, they have been taught more about reading strategies to improve reading efficacy. As a result, they were, to some extent, aware of the importance of using reading strategies and sometimes utilized them while reading. The findings showed that Vietnamese students were moderate strategy users, which is different from the result of a study conducted by Zare and Othman (2013) which found that Malaysian learners were high strategy users. This difference is quite understandable because English is used as a second language in Malaysia but a foreign language in Vietnam. Malaysian learners, therefore, have more opportunities to practice English everyday than their Vietnamese counterparts. Vietnamese learners only use English in the classroom and rarely use it outside schools. In addition, Malaysian students are more exposed to materials written in English, both at school and in daily life. They might also be taught more about reading strategies to overcome comprehension breakdowns. As a result, they read better and employ reading strategies more frequently and flexibly than Vietnamese students.

Of the three categories, students expressed preferences for cognitive and metacognitive reading strategies while using support strategies the least regularly. These findings are in line with some previous studies such as Sheorey and Mokhtari (2001), Zheng and Kang (2014) who also found that students were more in favour of cognitive and metacognitive strategies than support strategies. Cognitive reading strategies refer to actions or techniques directly solving problems connected to understanding so students considered these strategies the most helpful and often applied them to achieve comprehension. Similarly, metacognitive strategies like skimming, scanning, or guessing are often employed by learners while doing tests because they not only help students to read more efficiently but also save a great deal of time. Support reading strategies, in contrast, are regarded as "time-consuming strategies" (Zheng \& Kang, 2014), which probably prevent students from using them frequently.

Compared to other ESL learners, Vietnamese students share both similarities and differences in reading strategy use. Similar to Vietnamese learners, Turkish students (Yukselir, 2014) were in favour of skimming. However, several disparities were found between the two groups of ESL learners. While Turkish learners reportedly utilized the metacognitive strategy of "I determined what the type of the text is" frequently, their counterparts rated it as the least preferred. On the contrary, Vietnamese students preferred to use the cognitive strategy of " $I$ skipped unknown words", whereas Turkish students used this strategy the least. A study by Zheng and Kang (2014) investigated differences in the use of reading strategies between US and Chinese learners. The results showed that Chinese learners, like Vietnamese ones, employed reading strategies on the whole at a moderate level and used the cognitive strategy "re-reading for better understanding" and the metacognitive strategy "using prior knowledge" most regularly. However, Chinese participants, unlike Vietnamese students, considered "paying close attention to reading" as the least common strategy.

\section{Conclusion}

The results of descriptive statistics revealed that students moderately employed reading strategies while taking a reading test, and thus, they more or less realized the important role of reading strategies in improving their reading performance. Among three groups of strategies, students tended to apply cognitive strategies the most, followed by metacognitive and support ones. As for their preference for individual strategies, students reported using item number 14 
"I read the text again for better understanding." most often while rating item number 2 "I determined what the type of the text is." as the least preferred.

Based on the findings, it is suggested that teachers should encourage students to use reading strategies more often to develop their strategic knowledge. To make students become more strategic readers, teachers should carefully explain to students how and when to use the reading strategies efficiently by creating more opportunities for them to practice various strategies in different contexts. In addition, teachers should take cognitive and metacognitive reading strategies into consideration because they seem to work best for students in a testing environment.

Due to time constraints, the current study employed only a quantitative approach. This means that the collected data may not be truthful because students may have reported employing strategies they did not actually use. Therefore, further research should combine both quantitative and qualitative methods, for example a follow-up interview or think aloud protocol, to triangulate the pool of data.

\section{References}

Afflerbach, P., Pearson, P. D., \& Paris, S. G. (2008). Clarifying differences between reading skills and reading strategies. The Reading Teacher, 61(5), 364-373.

Asmara, N. I. (2017). An analysis of cognitive reading strategies used in reading comprehension. Advances in Social Science, Education and Humanities Research, 82, 304-307.

Carrell, P., Devine, J., \& Eskey, D. (1984). Interactive approaches to second language. Cambridge, UK: Cambridge University Press.

Garner, R. (1987). Metacognition and reading comprehension. Norwood, Australia: Ablex Publishing.

Johnston, T., \& Kirby, J. R. (2006). The contribution of naming speed to the simple view of reading. Reading and Writing: An Interdisciplinary Journal, 19(4), 339-361.

Kindler, A. (2002). Survey of the states' limited English proficient students and available educational programs and services: 2000-2001 summary report. Washington, DC: National Clearinghouse for English Language Acquisition.

Kletzien, S. B. (1992). Proficient and less proficient comprehenders' strategy use for different top-level structures. Journal of Reading Behavior, 24(2), 191-215.

Leon, J., \& Tarrayo, V. N. (2014). "Cyber" reading in L2: Online reading strategies of students in a Philippine public high school. Journal on English Language Teaching, 4, 8-17. doi:10.26634/jelt.4.2.2793

Macaruso, P., \& Shankweiler, D. (2010). Expanding the simple view of reading in accounting for reading skills in community college students. Reading Psychology, 31(5), 454-471.

Mokhtari, K., \& Reichard, C. (2000). Development of metacognitive awareness of reading strategies inventory. Journal of Educational Psychology, 94(2), 249-259. 
Nguyen, T. T., \& Trinh, L. Q. (2011). Learners' metacognitive strategy use and reading comprehension: Insights from a Vietnamese context. I-manager's Journal on English Language Teaching, 1(1), 9-19.

O’Malley, J., \& Chamot, A. (1990). Learning strategies in second language acquisition. Cambridge, UK: Cambridge University.

Ouellettee, G., \& Beers, A. (2010). A not-so-simple view of reading: How oral vocabulary and visual-word recognition complicate the story. Reading and Writing: An Interdisciplinary Journal, 23(2), 189-208.

Oxford, R. (1990). Language learning strategies: What every teacher should know. New York, NY: New Bury House.

Oxford, R. (2004). Changing the face of EFL instruction through learning styles and strategies. In The Proceedings of the Thirteenth International Symposium on English Teaching (Vol. 1).

Ozek, Y., \& Civelek, M. (2006). A Study on the use of cognitive reading strategies by ELT students. The Asian ELF Journal, 14, 1-26.

Pani, S. (2004). Reading strategy instruction through mental modeling. ELT Journal, 58(4), 355-362.

Paris, S., Wasik, B. A., \& Turner, J. C. (1991). The development of strategic readers. Handbook of Reading Research, 2, 609-640.

Selinger, H., \& Shohamy (1989). Second language research method. Oxford, UK: Oxford University Press.

Sheorey, R., \& Mokhtari, K. (2001). Differences in the metacognitive awareness of reading strategies among native and non-native readers. System, 29(4), 431-449.

Vo, T. T., Luu, M. H., \& Luu, N. T. B. (2014). An inquiry into students' application of metacognitive strategies in reading technical materials. Language Teaching and Research, 5(6), 1283-1291.

Yaemtui, W. (2015). Investigating reading strategies utilized by able English users and less able English users of Thai EFL students. International Forum of Teaching and Studies, 11(1), $55-68$.

Yukselir, C. (2014). An investigation into the reading strategy use of EFL prep-class students. Procedia-Social and Behavioral Sciences, 158, 65-72.

Zare, P., \& Othman, M. (2013). The relationship between reading comprehension and reading strategy use among Malaysian ESL learners. International Journal of Humanities and Social Science, 3(13), 187-193.

Zheng, J., \& Kang, N. (2014). An investigation on English reading strategy use in major-related materials among native and foreign language learners. Language Teaching and Research, 5(2), 283-290. 